Narrow sharply-defined rays were remarked to shoot up on several occasions from the horizon; these gradually widened out, losing their sharp boundaries and becoming less distinct, some times behaving like the cloud-like masses or becoming intensified by a "brush discharge" occurring across them; at others they faded gradually away.

At about 12.30 they had all disappeared, but a bright glow to the north horizon and faint glows at intervals over the sky between north and west.

It was not observed how far the discharges extended eastward. 24, Wa erloo Road, Dublin GERARD A. KinAHAN

THE following details of this evening's remarkable aurora may be of interest to your readers. At 6.45 p.m., while the new moon was setting, there was an appearance of a belt of luminous white cloud reaching along the northern and north. western horizon, giving indications of a tendency to divide into two separate parts, of which the western one had its upper surface parallel with the horizon, but that to the north was arched. From both parts rays and vertical bands of white light began to shoot upwards, reaching nearly to the zenith, and becoming more and more distinct, especially in the north (as opposed to the north-west), and one long feathery streamer was very conspicuous, and reached in a slanting direction from a point on the horizon immediately under the Pole Star up to Capella.

In the meantime the cloud-like appearance to the north-west had spread upwards over the heavens and assumed a dark ruddy colour, which gradually became brighter and more rosy, until it exactly resembled the light of dawn or sunset, which is sometimes reflected on the opposite side of the sky to the rising or setting sun. At this time the northern heavens became suffused with white light extending over the space where the bands and rays had been appearing, which throbbed repeatedly and vividly like the electric discharge in a vacuum tube, continuing some minutes. This gradually faded away, and the pink light to the north-west also disappeared by degrees, so that within twenty or twenty-five minutes from the commencement (say at about five or ten minutes past seven) there was little to be seen but a hardly noticeable light along the north horizon.

Mells Park, Somerset, January $3 \mathrm{r}$

IT may interest your readers to know that the auror a of January $3 \mathrm{I}$ was distinctly seen by me here at about seven o'clock on that evening. Such a sight is so uncommon in this part of London that I had some difficulty in convincing my friends that it was the aurora. As I walked down the Wickham Road, Brockley, towards Greenwich, broad bands of light shot up from the northern regions and reached nearly to the zenith. Descending amongst the fog and smoke that overhung the lower parts of New Cross, the light gradually faded, and I saw no more of it.

Aske's Hatcham Schools, Hatcham, February 4

W. J. SPRATLING

THE aurora of January $3 \mathbf{I}$ was well seen here. It was at its brightest at $6.40 \mathrm{p} . \mathrm{m}$. It extended from about north-west to nearly east. In the north-west and to the north of the crescent moon there was a large irregularly. shaped patch of sreenish phosphorescent light. Then round from it towards the north rose crimson streamers towards the zenith. The streamers continued round to the east nearly, still ascending zenithward, but white rather than crimson, between north-east and east. The streamers changed every instant, but the large greenish patch of light in the north-west was steady for some minutes.

It would be interesting to know whether observers in America noticed any unusual solar activity at the same absolute time as the aurora was occurring here, and also whether the magnetic elements in both hemispheres (north and south) showed disturbances in sympathy.

Raleigh Lodge, Exmouth, February 4

\section{GAS AND ELECTRICITY AS HEATING AGENTS}

II.

GAS engineers have been under the impression until now that a supply of cold air was favourable to the production of a brilliant flame. This is a misconception, which was very general also as regards the combustion of solid fuel in furnaces, until

${ }^{\prime}$ A lecture by C. William Siemens, D.C.L., LL.D., F.R.S., on January 27, in St. Andrews Hall, Glasgow, Science Lecture Association. Continued from p. 329. it was dispruved by Stirling, by Neilson, and by the introduction of the Regenerative Gas Furnace. The "duplex burner" owes its brilliancy to the heating effect of the one burner upon the other; and my brother, Mr. Frederick Siemens, has more recently constructed a burner in which the flame of the gas is reversed in its action in order to heat in its descent the ascending current of flame-supporting air.

By the application of the principle of conduction before described, I obtain the hot-air current in a most simple manner without interfering with the free action of the flame. The construction of my burner will bo seen from the diagram. $A$ is an ordinary Argand burner, taking its supply of gas through the enlarged vertical copper tube B. This copper pipe terminates in a rod $\mathrm{c}$ of highly conductive copper, which passes upward through the burner, and carries at its top a ball of porcelain or other refractory material. The rod is coated with platinum or nickel to prevent oxidation when heated (almost to redness) by the heat of the flame. The tube $\mathrm{B}$ is armed with radial plates of copper presenting a considerable aggregate surface, and abutting externally against a covering of asbestos or other non-conductive material.

The waste heat of the flame, or that portion of the heat produced in combustion which is not utilised in luminous rays, serves to heat the ball of refractory material $\mathrm{D}$ and the conductive rod c. The heat is thus transferred by conduction to the tube $\mathrm{B}$, with its laminar radii, between the extensive surfaces of which currents of air are free to ascend toward the Argand burner. The air is thus heated to from $700^{\circ}$ to $800^{\circ} \mathrm{F}$. before meeting the gas, and the ultimate temperature of the flame is increased to at least the same amount, causing a larger proportion of the heat developed in combustion to reach the point of luminous radiation.

But not only the quantity of light but its quality is improved by the higher temperature obtained.

It may appear surprising, but it is a fact susceptible of accurate proof, that the light obtained in consumption of a given amount of gas may thus be increased by some 40 per cent., and that in this large proportion the deleterious influences connected with gas lighting may be diminished. Gas will thus be better able to hold its position against its more brilliant rival the electric light, except for such large applications as the lighting of public halls and places, of harbours, railway stations, warehouses, \&c , for which it is pre-eminently suited. Add to these improved applications of gas the ever-increasing ones for heating purposes, and I have only to express regret that I am not a gas shareholder.

If gas is to be largely employed, however, for heating purposes, it will have to come down in price; and considering that heating gas need not be highly purified, or possessed of high illuminating power, the time will come, I believe, when we shall have two services, one for illuminating, and the other for heating gas.

In many towns two systems of gas mains already exist; and it would only be necessary to appropriate the one for illuminating and the other for heating gas. The ordinary retorts could be used for the production of both descriptions of gas, it being well known that even ordinary coal will give up gases of high illuminating power during a certain portion of the time occupied in their entire distillation. The gases emitted from the retor when first charged are to a great extent occluded gases of low illuminating power such as fire-damp or marsh-gas, and these should be turned into the heating mains. In the course of half-an-hour these occluded gases, together with the aqueous and other vapours, will have left the coal, which is then in the best condition to evolve olefiant gas and other gases rich in carbon, and therefore of high illuminating power. The period during which such illuminating gases are emitted extends over probably two hours, after which the retorts 'should again be connected with the heating gas mains, until the end of the process. The result of this modus operandi would be that the illuminating gas supplied, say in London, from Newcastle coal would probably exceed 20 candle power, instead of 16 as at present, whereby the objectionable results of gas lighting would be greatly diminished, and there would be, say, an equal volume of heating gas available, consisting for the most part of marsh-gas, which,although greatly inferior to olefiant gas in illuminating effect, would be actually more suitable for heating purpose:, because iess liable to produce soot in its combustion.

The total cost of production would not be increased by this separation of the gases, and the price might with advantage 
both to the supplier and to the consumer be so adjusted that the latter, while paying for his illuminating gas an increased price proportionate to the increase of illuminating power, would be furnished with a heating gas at greatly reduced cost; for the heating gas could be reduced in price in a much larger proportion than the illuminating gas would have to be raised, because it would not require the same purification from sulphur which renders illuminating gas comparatively costly. The enormous increase of consumption would moreover enable the gas companies to reduce prices all round very considerably without interfering with their comfortable revenues.

For large applications of heating gas to the working of furnaces and boilers, simpler means than the retort can be found for its produc:ion. I constructed a gas producer many years ago in connection with my Regenerative Gas Furnace; this I need not now describe in detail. In it all the carbonaceous matter of the coal is converted into combustible gas, the solid carbon yiclding a supply of carbonic oxide ; the resultant mixture of combustible gas contains a very large proportion averaging $6 \mathrm{I}^{\circ} 5$ per cent. of nitrogen, which swells its volume without in any way contributing to its heating power.

It has been my endeavour for some time to construct a gas producer which, without losing the simplicity of the first, should be capable of yielding a heating gas of superior calorific power. This producer consists of a wrought-iron cylindrical chamber, truncated downwards, and lined with brickwork. The fuel to be converted into gas is introduced through a hopper, and the cinder and ashes work out through the open orifice at the bottom.

Instead of a grating for the introduction of atmospheric air a current of heated air is brought in, either through the hopper or through the orifice at the bottom, and is discharged into the centre of the mass of fuel ; the effect is the generation of a very intense heat at that point. The fuel, after its descent through the hopper, arrives gradually at this region of intense heat, and when subjected to it, parts with its gaseous constituents. At the point of maximum heat coke is consumed, producing sarbonic anhydride, which, in passing through the considerable thickness of fuel surrounding this portion, takes up a second equivalent of carbon, and becomes changed into carbonic oxide. Here also the earthy constituents are for the most part separated in a fused or semi-fused condition, and in descending gradually reach the orifice at the bottom, whence they are removed from time to time. Air enters through the bottom orifice to some extent, causing the entire consumption of the carbonaceous matter, which may have got past the zone of greatest heat; water is also here introduced in a hollow tray, and after evaporation by the heat of the hot clinkers, passes upwards through the incan. descent mass, and is converted by decomposition into carbonic oxide and hydrogen gas. The exit orifices for the gases are placed all round, near the circumference of the chamber, ascend. ing upwards into an annular space, whence they are taken through pipes ta the furnace or other destination.

The advantages connected with this modus operandi consist in the intensity of the heat produced within the centre of the mass, whereby the whole of the fuel is converted into combustible gases, with the least amount of nitrogen. The hydrocarbons formed in the upper portion of the apparatus have to descend through the hotter fuel below, and in so doing the tar and other vapours mixed up with them are decomposed, and furnish combustible gases of a permanent character.

The orifice at the bottom of the apparatus may be enlarged, and so arranged that, instead of ashes only being produced, coke may be withdrawn, and in this way a continuous coke oven may be constructed, which is at the same time a gas producer, or in other words an apparatus in which both the solid and gaseous constituents of the coal are fully utilised.

The intense heat in the very centre of a large mass of fuel has for its result a very rapid distillation, and thus one gas producer does the work of two or three gas producers of the type hitherto employed; this more concentrated action will moreover allow of the introduction of gaseous fuel, where want of space and considerations of economy have militated hitherto against it, and in favour of the ordinary coal furnace.

It has been already proved that steam boilers can be worked economically on land with gaseous fuel, and there is no reason that I know of why the same mode of working should not also be applied to marine boilers. The marine engine has, within the last fifteen years, been improved to an extent which is truly surprising : the consumption of coal, which at the com. mencement of that period was never less than $8 \mathrm{lbs}$. per HP., has been reduced by expansive working in compound cylinders to $2 \mathrm{lbs}$, or even less, per actual HP. The mode of firing marine boilers has, however, remained the same as it was in the days of Watt and Fulton. In crossing the Atlantic one may see a considerable number of men incessantly employed in the close stoke-hole of the vessel opening the fire doors and throwing in fuel. Each charge gives-rise to the development of great clouds of black smoke issuing from the chimney, to the great annoyance and discomfort of the passengers on deck. If, instead of this, the fuel could be discharged mechanically into one or more gas producers, the gaseous fuel produced would maintain the toilers at a very uniform heat, without necessitating the almost superhuman toil of the fireman; no smoke or dust would be emited from the chimney, and a large saving of fuel would be effected.

This charge would be specially appreciated by the numerous tourists visiting the Western Highlands. Speaking from my own experience on one occasion, I may say that the pleasure of a trip on the beautiful Loch Lomond was very seriously marred in consequence of the fumigation which my fellow passengers and myself had to endure.

The change from the use of solid to gaseous fuel would be the prelude probably to another, and still more important change, namely the entire suppression of the steam boiler. We are already in possession of gas-engines working at moderate expense as compared with small steam-engines, even when supplied with the comparatively expensive gas from our town gas-mains, and all that will be required is an extension of the principle of operation already established. The realisation of such a plan would of course involve many important considerations, and may be looked upon as one of those subjects the accomplishment of which may be left for the energy and inventive power of the rising generation of engineers.

Before leaving this branch of the subject I wish to call attention to a favourite suggestion which I had occasion to make some years ago. It consists in placing gas-producers at the bottom of the coal mines themselves, so that instead of having to raise the coal by mechanical power, the combustible gases ascending from the depth of the mine to the surface would acquire by virtue of their low specific gravity such an onward pressure that they could be conducted in tubes to distances of many miles, thus saving the cost of raising and transporting the solid fuel.

Glasgow with its adjoining coal-fields appears to me a particularly favourable locality for putting such a plan to a practical trial, and the well-known enterprise of its inhabitants makes me sanguine of its accomplishment. When thus applied with gaseous fuel, the town would not only be able to boast of a clear atmosphere, but the streets would be relieved of the most objectionable portion of the daily traffic.

I now approach another and the last portion of my address, the attainment of very intense degrees of heat either for effecting fusion or chemical decomposition. Although by means of the combustion of either solid or gaseous fuel heats are produced which suffice for all ordinary purposes, there is a limit imposed upon the degree of temperature attainable by any furnace depending upon combustion. It bas been shown by Bunsen and by St. Claire-Deville, that at certain temperatures the chemical affinity between oxygen on the one hand and carbon and hydrogen on the other absolutely ceases, and that if the products of combustion $\mathrm{CO}_{2}$ and $\mathrm{H}_{2} \mathrm{O}$ be exposed to such a degree of temperature they would fall to pieces into their constituent elements. This point of dissociation, as it is called, is influenced by pressure, but has been found for $\mathrm{CO}_{2}$ under atmospheric pressure to be $2600^{\circ} \mathrm{C}$. (or $4700^{\circ} \mathrm{Fahr}$.). But long before this extreme point has been arrived at, combustion is greatly retarded, and the limit is reached when the losses of heat by radiation from the furnace balance its production by combustion.

To electricity we must look for the attainment of a temperature above that of dissociation, and we have evidence of the early application of the electric arc to such a purpose. In 1807 Sir Humphry Davy succeeded in decomposing potash by means of an electric current from a Wollaston battery of 400 elements, and in 1810 he surprised the members of the Royal Institution by the brilliant electric arc produced between carbon points thrcugh the same agency.

Magneto-electric and dynamo-electric currents allow of the production of the electric arc much more readily and econo- 
mically than by the use of Sir Humphry Davy's gigantic battery, and Messrs. Huggins, Lockyer, Liveing, and other physicists have taken advantage of the comparatively new method to advance astronomical and chemical research with the aid of spectrum analysis.

My object is now to show that the heat of the electric arc is not only available within a focus or extremely contracted space, but that it is capable of producing such larger effects as will render it useful in the arts for fusing platinum, iridium, steel, or iron, or for effecting such reactions or decompositions as require for their accomplishment an intense degree of heat, coupled with freedom from such disturbing influences as are inseparable from a furnace worked by the combustion of carbonaceous material.

The apparatus which I employ to effect the electro-fusion of such material as iron or platinum is represented in the drawing. It consists of an ordinary crucible of plumbago or other highly refractory material, placed in a metallic jacket or outer casing, the intervening space being filled up with pounded charcoal or other bad conductor of heat. A hole is pierced through the bottom of the crucible for the admission of a rod of iron, platinum, or dense carbon, such as is used in electric illumination. The cover of the crucible is also pierced for the reception of the negative electrode, by preference a cylinder of compressed carbon of comparatively large dimensions. At one end of a beam, supported at its centre, is suspended the negative electrode by means of a strip of copper, or other good conductor of electricity, the other end of the beam being attached to a hollow cylinder of soft iron free to move vertically within a solenoid coil of wire, presenting a total resist. ance of about 50 units or ohms. By means of a sliding weight the preponderance of the beam in the direction of the solenoid can be varied so as to balance the magnetic force with which the hollow iron cylinder is drawn into the coil. One end of the solenoid coil is connected with the positive and the other with the negative pole of the electric arc, and, being a coil of high resistance, its attractive force on the iron cylinder is proportional to the electromotive force between the two electrodes, or, in other words, to the electrical resistance of the arc itself.

The resistance of the arc was determined and fixed, at well within the limits of the source of power, by sliding the weight upon the beam. If the resistance of the arc should increase from any cause the current passing through the solenoid would gain in strength, and the magnetic force overcoming the counteracting weight would cause the negative electrode to descend deeper into the crucible; whereas, if the resistance of the arc should fall below the desired limit, the weight would drive back the iron cylinder within the crils, and the length of the arc would increase, until the balance between the forces engaged had been re-established.

Experiments with long solenoid coils have shown that the attractive force exerted upon the iron cylinder is subject only to slight variation within a range of several inches, which circumstance allows of a working range to that extent of nearly uniform action on the electric arc.

This antomatic adjustment of the arc is of great importance to the attainment of advantageous results in the process of electric fusion; without it the resistance of the arc would rapidly diminish with increase of temperature of the heated atmosphere within the crucible, and heat would be developed in the dynamo-electric machine to the prejudice of the electric furnace. The sudden sinking or change in electrical resistance of the material undergoing fusion would, on the other hand, cause sudden increase in the resistance of the arc, with a likelihood of its extinction, if such self-adjusting action did not take place.

Another important element of success in electric fusion consists in constituting the material to be fused the positive pole of the electric arc. It is well known that it is at the positive pole that the heat is principally developed, and fusion of the material constituting the positive pole takes place even before the crucible itself is heated up to the same degree. This principle of action is of course applicable only to the melting of metals and other electrical conductors, such as metallic oxides, which constitute the materials generally operated upon in metallurgical processes. In operating upon non-conductive earth or upon streams of gases it becomes necessary to provide a non-destructible positive pole, such as is supplied by the use of a pole of fused platinum, or iridium, or by a plumbago crucible. In working the electric furnace some time is taken up in the first instance in raising the temperature of the crucible to a considerable degree, but it is surprising how rapidly an accumulation of heat takes place. In using a pair of dynomo-machines capable of producing 70 webers of current with an expenditure of 7 -horse power, and which, when used for purposes of illumination, produce a light of 12,000 candles, a crucible of about 8 inches in depth, immersed in a non-conductive material, has its temperature raised to a white heat in fifteen minutes, and 4 lbs. of steel are fused within another fifteen minutes, successive fusions being effected in somewhat diminishing intervals of time. The process can be carried on on a still larger scale by increasing the power of the dynamo-machines and the size of the crucibles.

The purely chemical reaction intended to be carried into effect within the crucible might be interfered with through the detachment of particles from the dense carbon used for the negative pole, although its consumption within a neutral atmosphere is exceedingly slow. To prevent this I have used, both in this con. nection and also in the construction of electric lamps, a water pole, or tube of copper, through which a current of water circulates, so that it yields no substance to the arc. It consists simply of a stout copper cylinder closed at the lower end, having an inner tube penetrating to near the bottom for the passage of a current of water into the cylinder, which water enters and is dis. charged by means of flexible india-rubber tubing. This tubing being of non-conductive material, and its sectional area small, the escape of current from the pole to the reservoir is so slight that it may be neglected. On the other hand some loss of heat is incurred, through conduction, with the use of the water pole, but this loss diminishes with the increasing heat of the furnace, inasmuch as the arc becomes longer, and the pole is retired more and more into the crucible cover.

In the experiments which I shall now place before you the current which has supplied the one electric lamp in the centre of the hall will be diverted by means of a commutator through the electric furnace. After it has been active for five minutes to warm the crucible, I shall charge it with $8 \mathrm{lbs}$. of broken steel files, which I shall endeavour to melt and pour out into an ingot mould before your eyes.

By some obvious modifications of this electric furnace it can be made available for a variety of other purposes where intense heat is required combined with immunity from disturbing chemical actions. By piercing a number of radial holes through the sides of the chamber, and introducing the ends of wires through the same, an excellent means is provided of heating those wire ends very rapidly, without burning them, for the purpose of welding them together. The electrical furnace will also be found useful, I believe, in the hands of the chemist to effect those high temperature reactions between gaseous lodies which require the employment of temperatures far exceeding the hitherto available limits, and will thus increase the area of available reactions at his disposal for the attainment of either scientific or practical ends.

I have endeavoured to compress within the limited space of a single lecture, subject matter that might occupy the close attention of the student for weeks or months, and I may therefore be pardoned if I have failed to convey to you more than a very rough outline of what may be accomplished by the judicious use of gaseous fuel, and of the electric current, as heating agents. The one purpose that has been foremost in my mind in preparing this lecture, has been to make war upon the smoky chimney, which, so far from being a necessity under any circumstances whatever, should be regarded only as a remnant of that stage of our industrial and social progress which satisfied with the attainment of certain ends, could afford to neglect the economical and sanitary conditions under which those ends were accomplished.

The Exhibition which has lately been held in this city of appliances for heating and illuminating by means of gas and elestricity, in which your President, my esteemed friend, Sir William Thomson, took so prominent a part, as he does in everything tending towards the advancement of human knowledge and well-being-proves how deep is the interest felt amongst you in those very questions with which I have had to deal this evening.

And so I thought you might not be disinclined to give attention nnce more to a particular view of the question, which happens to be the result of the independent labour of one who may claim at any rate to have given a life-long attention to the subject. 